\title{
eLyra
}

\section{A máscara e o eco: música e (auto)biografia em Marilyn Moore, de Manuel de Freitas}

\author{
Patrícia Chanely Silva Ricarte \\ Universidade Federal de Minas Gerais
}

Resumo: Na obra contemporânea do poeta português Manuel de Freitas, tem grande relevo a referência ao universo musical, em especial no que se refere a canções populares e a experiências de seus compositores e intérpretes. Neste artigo, abordarei um dos elementos ligados a esse fenômeno, a saber: o recurso à ficcionalização poética da biografia de artistas da música em Marilyn Moore, coletânea de poemas publicada por Freitas em 2011, e dedicada à cantora de jazz estadunidense que dá nome ao livro. Trata-se, a meu ver, de um processo em que o texto poético é concebido como eco e reverberação da experiência musical e que, ao mesmo tempo, dá vazão ao enfoque metapoético, por meio do artifício da máscara alegórica e da escritura "em dueto".

Palavras-chave: Poesia portuguesa contemporânea, Manuel de Freitas, música, biografia, autobiografia

\begin{abstract}
In the contemporary work of the Portuguese poet Manuel de Freitas, the reference to the musical universe, especially regarding popular songs and the experiences of their composers and interpreters, has great importance. In this article, I will discuss one of the elements related to this phenomenon, namely: the poetic fictionalization of some musician's biographies in Marilyn Moore, a collection of poems published by Freitas in 2011, and dedicated to the American jazz singer who gives name to the book. It is, in my view, a process in which the poetic text is conceived as an echo and reverberation of the musical experience and that, at the
\end{abstract}


same time, propitiates metapoetic approach, through the artifice of the allegorical mask and the writing "in duet".

Keywords: Contemporary Portuguese poetry, Manuel de Freitas, music, biography, autobiography

Em memória do Júnior, querido irmão, que sabia entregar-se ao fascínio das canções.

Em seu livro de ensaios Em parte incerta, a crítica portuguesa Rosa Maria Martelo (2004: 239) assinala, na poesia portuguesa produzida nas últimas décadas, o interesse pela "sugestão de realismo ou de sinceridade", o qual culmina em "uma relação de cumplicidade com o leitor que a Modernidade estética não pudera senão excluir". Segundo esta autora,

[...] a exploração de novas formas de lirismo e o desenvolvimento de uma poesia da experiência parecem surgir, de facto, em articulação com a desvalorização da ideia de ruptura como condição de evolução estética, e também com uma consciência de crise das utopias e com o reconhecimento da erosão de versões-de-mundo ontologicamente fortes, às quais o recolhimento do sujeito nos horizontes mais circunscritos da individualização da experiência poderia constituir uma possível resposta. Por outro lado, a revalorização da enunciação lírica pode ainda, neste contexto, ser articulada com o facto de estarmos perante um momento de forte questionamento da condição de autonomia do poema, tal como fora formulada no contexto da Modernidade estética, particularmente pelo Simbolismo e pelo Modernismo, e, em certa medida, posteriormente recuperada pelas chamadas neo-vanguardas da década de 1960. (Martelo 2004: 243-244)

É nesse contexto que, conforme Martelo, vamos encontrar a obra de Manuel de Freitas, o qual, como editor, crítico e poeta, tem dado relevo ao "desejo de comunicar" como forma de renovação do lirismo, "frequentemente articulável com a valorização de uma relação mais imediata, ou mais legível, com a experiência e, por consequência, capaz de uma maior cumplicidade com o leitor" (Martelo 2004: 243). Isto é o que se pode observar, por exemplo, no poema "Zulmira, ao amanhecer", do livro Os Infernos Artificiais, em que, numa 
visada baudelairiana, o sujeito poético irmana-se com a gente comum e simples das ruas, como a dona de uma tasca, os mendigos e marginais que encontra após uma noitada, em detrimento daqueles que ironicamente trata por "puetas":

No urinol público lia-se utilização gratuita.

Fiquei quase feliz (quantas coisas gratuitas

há neste mundozinho de horror?).

Mas o que desta manhã eu mais agradeço, Zulmira,

é a tua sopa, essa que tantas vezes

me salvou a vida, entre centenas de super bocks.

Não me inquietam os chulos, os assassinos

ou estes mendigos calados. Ilustríssima gente,

de uma má-raça inegável. Prefiro perder

com eles os meus dias, e falar da fome, dos joanetes

ou do preço do azeite. Não tenho tempo

para aprofundar desrazões, nem para conviver com puetas.

Sei apenas que as poucas pessoas que amei

estavam por detrás de um balcão

onde o álcool ardia, muito devagar.

Os meus pobres anjos.

Também por isso gostava de te obrigar a esta taberna,

exílio cantante de todas as minhas antigas manhãs.

Por esta mãe desolada, pelo rumor sombrio

do vinho que nunca azedou nos meus lábios,

por certas inábeis palavras que sobre os barris

faleceram e te pertenciam somente.

Mas "até logo, Zulmira", bem sabes que do amor

ou do futebol nada poderei jamais dizer

ou sentir. Entre os teus braços largos deponho

em silêncio aquela negra noite do meu mal.

Por uma sopa encorpada, sobre destroços

imperecíveis, bocados de morte partidos. (Freitas 2007: 42-43) 
Em outros textos de Freitas, pode-se observar a visão decadente e niilista do amor, diante de uma vivência contemporânea marcada pelo tédio e por uma boemia desiludida, como em "Duas vezes nada", poema de [Sic]:

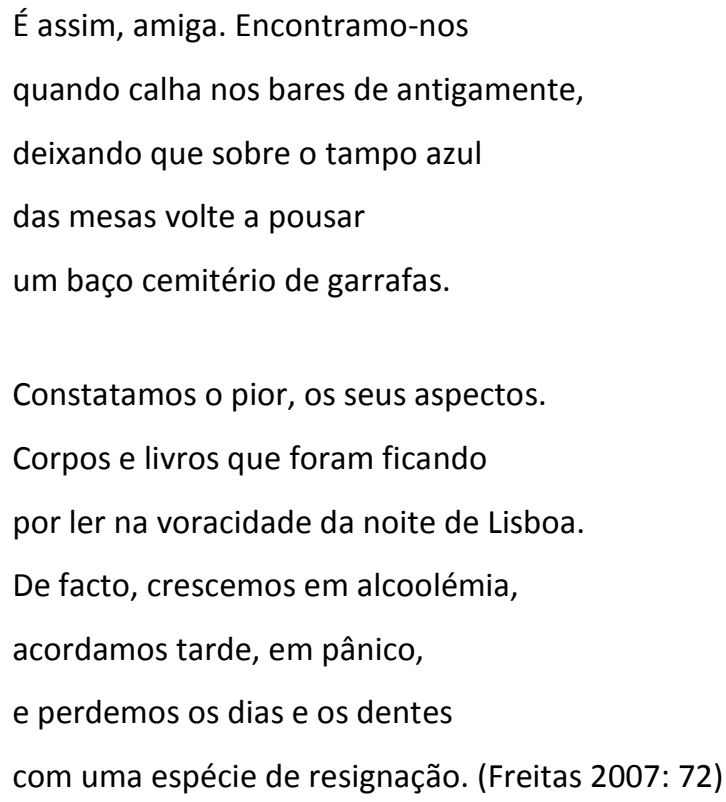

Assim, acaba-se por confirmar aquela cumplicidade com o leitor sublinhada por Rosa Martelo, em razão do despojamento com que o poeta traz para os seus textos experiências banais e comuns a quem está inserido na vida urbana de nossos dias.

De minha parte, destaco, nessa poesia, o diálogo com o universo musical, em sua recorrente referência a vertentes do pop e à obra de Johann Sebastian Bach. Em Freitas, o interesse pela carga existencial da música, passando pela biografia do artista, reflete uma forma de resgatar para a poesia certo realismo. Trata-se, para Joaquim Manuel Magalhães (apud Vasconcelos 2010), de um efeito de sinceridade responsável por estabelecer a figuração de um sujeito cuja experiência vivencial precede o poema.

De fato, em "Arte Poética I", texto de Game Over, livro de 2002, Freitas, em franco diálogo com o poema "Grafia 1", publicado por Fiama Hasse Pais Brandão em Morfismos, obra pertencente à coletânea coletiva Poesia 61, joga com o processo de significação das palavras:

Ao escrever ave

não estou a escrever 
cigarro,

tinteiro,

vazio.

O real é contundente,

de acordo,

mas que dizer das palavras?

(De resto, será o "real"

assim tão real?)

Tinteiro é coisa que já

não se usa, ave ainda

- mas nem sempre bem.

E o cigarro entretanto ardeu. (Freitas 2007: 56)

Primeiramente, o poeta remete ao processo de diferenciação dos signos: "Ao escrever ave / não estou a escrever / cigarro, / tinteiro, / vazio", como resposta ao intenso deslizamento de significantes proposto por Fiama em seu texto:

Água significa ave

se

a sílaba é uma pedra álgida

sobre o equilíbrio dos olhos

se

as palavras são densas de sangue

e despem objectos

se

o tamanho deste vento é um triângulo na água

o tamanho da ave é um rio demorado

onde 
as mãos derrubam arestas

a palavra principia (Brandão apud Silveira/Maffei 2011)

Em seguida, questiona-se, no poema de Freitas, a contundência do real, em razão de sua mediação pelas palavras, como uma espécie de réplica ao que é postulado pelo poema de Fiama, o qual problematiza a simetria saussureana entre significante e significado. Por fim, afirma-se que o real existe à revelia da palavra: "E o cigarro entretanto ardeu". Contudo, é ainda com palavras que, paradoxalmente, se pode fazer uma asserção dessa natureza.

\section{Desistir do rosto}

Imerso na atmosfera melancólica e decadente das canções pop contemporâneas, Manuel de Freitas traz para o texto do poema a associação do tema musical ao ambiente das tabernas, ao tédio e à solidão regados a álcool e demais entorpecentes artificiais de nosso tempo, numa releitura do decadentismo finissecular dos oitocentos, como se pode observar no poema "But not for me (Billie Holiday)", também presente no livro [Sic], de 2002, e que é homônimo a uma canção interpretada pela referida cantora norte-americana de jazz: ${ }^{1}$

\footnotetext{
Desistir do rosto, dos propósitos, das

palavras. Há sílabas assim.

Com a vergonha do afecto

emprestada ao desalinho das mesas.
}

Por ali, encenando a imobilidade,

a rudeza de haver dor.

Eu sei que não virás.

Bebo por ti, sem ti, contra ti,

com o coração no bengaleiro

a fingir que não, não faz diferença.

E o pior é que até faz,

por muito que ninguém o saiba. (Freitas 2007: 69)

Neste poema, o diálogo com a letra de Billie Holiday, em que a voz do sujeito poético feminino se ressente das canções de amor que não foram feitas para si, mas para outras 
mulheres, se dá a partir de uma identificação com outro dado biográfico da cantora: a vida etílica ou boêmia. Contudo, tal elemento combina-se, no texto de Freitas, com uma visada metapoética, a qual é passível de gerar um duplo sentido entre o objeto amoroso e a própria poesia: "Eu sei que não virás. / Bebo por ti, sem ti, contra ti, / com o coração no bengaleiro / a fingir que não, não faz diferença". Reside aí, a meu ver, certa complicação do traço de "experiência vivencial" com que se tem frequentemente descrito a obra de Freitas.

Segundo Vasco André Ribeiro de Vasconcelos, em dissertação de mestrado sobre as referências musicais na poesia de Manuel de Freitas, assim como o poeta que perde a auréola em Baudelaire,

[o] sujeito que se revela na poesia de Manuel de Freitas também é um frequentador de lugares que alguns poderiam descrever como reles - bares e tabernas, claro está. E é também frequentador de eventos musicais que, muitas vezes, pouco terão de erudito (salvo as devidas e significativas excepções que não deixarão de merecer comentário). É mais um numa multidão que se constitui como um corpo mundano, prosaico e popular. Como pode ser mundana, prosaica e popular a música que aí se ouve. (Vasconcelos 2010: 15)

Cabe, entretanto, salientar, quanto à obra de Freitas, a ambiguidade que caracteriza o artifício da máscara, esse ato de esconder o rosto por trás da face de outrem, na medida em que tal expediente tende tanto à identificação (auto)biográfica quanto à metalinguagem ou à autoreferencialidade da linguagem poética. Nessa perspectiva, é válido retomar Paul de Man, no ensaio "Poesia lírica e modernidade", ao reforçar o caráter ao mesmo tempo simbólico e alegórico das imagens utilizadas pela poesia. Para o referido teórico, tais imagens, ao mesmo tempo em que representam objetos da natureza, são, na verdade, extraídas de fontes puramente literárias. Assim, patenteia-se a absoluta ambivalência da linguagem poética, que, na modernidade, se constitui como algo representacional e não representacional, ao mesmo tempo:

Toda a poesia representacional é sempre também alegórica, quer disso tenha consciência ou não, e o poder alegórico da linguagem mina e obscurece o significado literal específico de uma representação aberta à compreensão. Mas toda a poesia alegórica deve conter um elemento representacional que convida e permite essa compreensão apenas para mais tarde descobrir que a compreensão a que chega está necessariamente errada (Man 1999: 206) 
Na poesia de Freitas, o músico é o sujeito que vai emprestar ao poema o lastro existencial de uma condição interessante em termos de vivência, a partir de um registro poético que se interessa muito mais pela profundidade do biográfico - e de tudo o que se pode ficcionalmente criar ou imaginar em torno de tal elemento - do que pelo que se convencionou como historicamente importante em certa tradição. No caso da história da poesia, basta lembrar como, mesmo ao longo do século $\mathrm{XX}$, marcado pelas mais diversas vanguardas, sempre teve peso e valor a ideia do tradicional. Nesse sentido, a eleição de um acervo de obras da indústria fonográfica, e não da moderna tradição poética majoritariamente impressa, já configura por si um desvio significativo em termos de posicionamento crítico por parte do poeta.

A esse respeito, destaca-se a quantidade expressiva de poemas nos quais Manuel de Freitas explora o aspecto biográfico de personagens ligados ao universo da música. Além de vários outros títulos ${ }^{2}$ do poeta em que tal procedimento ganha importância central, Marilyn Moore, livro de poemas publicado por Freitas em 2011, consiste em uma coletânea inteiramente inspirada na trajetória artística e pessoal da cantora de jazz norte-americana que dá nome à obra, como se pode notar em "Lover come back to me", texto homônimo a uma canção regravada por Moore em 1957: ${ }^{3}$

\footnotetext{
Na cama do hotel, em Tulsa, limitava-se

a trautear a canção em que prometera

dar o seu melhor, num esboço de epitáfio.
}

Percebia agora que há temas

que cantamos melhor deitados,

longe de qualquer palco.

Bebeu um copo de Woodford, para trazer um pouco mais de sombra à voz.

Não podia adivinhar, em Tulsa, que

a volúpia em breve se tornaria uma súplica,

o género de coisas que só dizemos a ninguém. (Freitas 2011: 16) 
O recorte biográfico, neste e em outros poemas do mesmo livro, focaliza uma cena íntima da personagem, propiciando o descortinar do elo visceral entre as vicissitudes existenciais do sujeito e a experiência do canto, a partir de um senso de fatalidade que faz convergir para o mesmo estado de melancolia todos os elementos da cena: a solidão, a sombra da voz, a bebida alcoólica, a volúpia do presente e a antecipação, por parte do sujeito poético, de uma súplica amorosa futura.

Cabe, ainda, salientar que a referência à condição boêmia de músicos e poetas dá vazão, na poética de Freitas, ao enfoque da música em sua relação com o estado de angústia ou desolação e com o sentido da morte ou da perda: “A música / deteriorou-se, apodreceu devagar / nas mãos com que te perco a ti, / bebendo contigo a festa da tua ausência" (Freitas 2010: p. 40) ou “A música era esta. / Perdemos quase tudo" (idem: 102). O sentido dessa perda é, ao mesmo tempo, um problema da escritura poética contemporânea, que jaz privada de sua função de canto: "Não me subscrevo, não gosto de dizer / o que digo, só muito arduamente / a escrita se desaprende. E é improvável cantar" (idem: 41). O poema "o fingido poema em que a ruína se exalta" (ibidem) - se faz a partir da consciência dessa perda do canto ou da música. Nesse sentido, a referência à música extrapola a mera tematização cultural e atende a uma reflexão acerca da linguagem e do fazer poéticos.

Portanto, pode-se, a meu ver, estender a questão da vocalidade musical também ao âmbito específico da poesia literária na contemporaneidade, cujo traço existencial, marcado pela corporeidade e, por conseguinte, pela terrestridade e mortalidade, é assumido justamente pela consciência poética da perda do canto e pela ascensão de uma voz cada vez mais prosódica. Afinal, ao perder a pretensão ao canto, a poesia não se afasta necessariamente da noção de vocalidade, embora trate-se, agora, da oralidade do escrito, e de uma voz mais propriamente falada do que cantada. De acordo com Henri Meschonnic (2009), a matéria da oralidade é a voz, e não a respiração, como boa parte de poetas e teóricos tem sustentado, por meio das mais variadas metáforas, ao definir o ritmo da poesia. Além disso, segundo o mesmo autor, e também como os próprios desenvolvimentos das formas poéticas na modernidade têm nos mostrado, o ritmo da poesia é diferente do ritmo da música porque se constitui como discurso, e não como metro. 
Em “Trav'lin' all alone”, título emprestado de outra canção ${ }^{4}$ interpretada por Moore, mais uma vez, a experiência pessoal da artista é lida como algo expresso em sua performance vocal:

\author{
Entre o presságio e o fascínio, \\ muito lhe deve ter doído \\ aquele solo inicial de saxofone, \\ Depois, é a sua voz que \\ vai ficando sozinha, \\ cada vez mais sozinha. \\ Até por fim se confundir \\ com a noite. (Freitas 2011: 22)
}

Trata-se, tanto no poema quanto na letra da referida canção de jazz, de um estado de extrema solidão. No caso do poema, coaduna-se a esse estado o pressentimento de uma desilusão amorosa, já insinuado ao ouvinte da canção, que diz: "Trav'lin', trav'lin' all alone / Prayers are said to heaven above / 'bout my burdens, woes and love" ["Viajando, viajando sozinha / Orações são proferidas para o céu acima / Sobre meus fardos, desgraças e amor"]. O "solo inicial de saxofone" mencionado no poema refere-se à performance de Al Cohn, músico com quem Moore casara-se em 1953, tendo com ele dois filhos, e de quem se divorciou em 1958. Nos textos de Marilyn Moore, Freitas explora especialmente cenas relativas à crise amorosa da cantora em torno dessa separação.

Contudo, se tomamos estes mesmos elementos como alegoria, essa "voz que / vai ficando sozinha, / cada vez mais sozinha" pode referir-se ao próprio estado da poesia, que sofre, em nossa época, um substancial despojamento, sobretudo no que concerne aos elementos musicais que tradicionalmente caracterizam o verso. Assim, a crise existencial da personagem que canta ou que performatiza, em sua biografia, a verdadeira experiência musical acaba por refletir, de modo sensível e sutil, a condição da poesia e do poeta de agora. Em "Cocset, 2002", poema do livro Büchlein für Johann Sebastian Bach, poeta e músico compartilham o mesmo destino: 


\author{
Tão depressa a morte cairá \\ sobre este poema. Recorda, \\ porém, a buganvília que abraçava \\ a varanda da casa e os amigos \\ todos que lá iam. Volta a sentir \\ na tua mão o peso das mãos \\ que um dia tiveram a destreza \\ do arco sobre as cordas \\ - à mercê de uma música sem saída. (Freitas 2010: 77)
}

Além disso, dado o aspecto de máscara que a biografia de personagens do universo musical assume na obra de Freitas, torna-se plausível relacionar esse gesto de ficcionalização com o tropo da prosopopeia, que, na acepção de Paul de Man, em outro de seus ensaios, encobre o rosto do próprio poeta por meio de uma desfiguração. De acordo com este autor, a figura da prosopopeia é

a ficção de uma apóstrofe a uma entidade ausente, falecida ou sem voz, a qual confere a possibilidade de que esta entidade possa replicar e lhe confere o poder da palavra. A voz assume uma boca, um olho e finalmente uma face, uma cadeia que é manifesta na etimologia do nome do tropo, prosopon poiein, para conferir uma máscara ou uma face (prosopon). A prosopopeia é o tropo da autobiografia, com a qual o nome de alguém [...] é tornado inteligível e memorável com uma face. Nosso tópico lida com pôr e depor faces, com figurar [face] e desfigurar [deface], figura, figuração e desfiguração. (Man 2012)

No ensaio "Modernidade e senso comum", Rosa Martelo explora esse conceito de Paul de Man para definir a experiência do sujeito poético como algo partilhado ou facilmente partilhável na contemporaneidade:

a des-figuração do sujeito pode não implicar agora uma retórica da impessoalidade e uma actualização figural, em termos de tessitura discursiva, e pode reverter para a construção de personagens facilmente reconhecíveis para o leitor como des-figurações identitárias referenciáveis no seu mundo habitual. Por conseguinte, o efeito de dissolução identitária não será agora muito diferente: o que acontece é que pode ser objecto de uma tematização que pressupõe que o leitor construa um efeito de realismo que estava ausente do abstraccionismo lírico da Modernidade. De resto, o acentuado discursivismo que caracteriza muita da poesia do último quartel do século XX poderá mesmo constituir 
uma estratégia destinada a suster a des-figuração identitária e a reconhecida fragilidade do sujeito. (Martelo 2004: 225)

Nessa perspectiva, pode-se pensar a referência à música por meio da ficcionalização de biografias como um modo indireto ou desfigurado de autorreferência à poesia, no qual o elemento metapoético converge com o traço da autobiografia, ambos sob as máscaras de personagens ligadas ao universo musical. A esse respeito, vale lembrar o trabalho de ilustração da artista plástica Adriana Molder que integra a coletânea Marilyn Moore, de Freitas, constituído por três desenhos que representam a cantora norte-americana, sendo que o primeiro deles, presente na capa e na página nove do livro, intitula-se justamente "Máscara". Assim, o gesto de tomar emprestados à artista da música o rosto e a biografia revela certo traço desconstrucionista por parte do poeta, em que pese a visada "realista" que boa parte dos estudiosos de sua obra sublinha acerca de seu trabalho com a linguagem.

\section{Duas vozes se encontram tão perto do silêncio}

Em um dos poemas da referida coletânea, esse jogo de máscaras é representado pelas figuras de Marilyn Moore e Billie Holiday, sendo que o encontro entre as duas artistas pode ser tomado, a meu ver, como símbolo do diálogo entre a poesia e a música ou entre o poeta e a tradição, entendendo-se esta última como eminentemente musical:

\footnotetext{
"I’m just a lucky so and so"

Se enriqueceu, o que é duvidoso,

terá sido de outra maneira,

depois de 1957 - o mesmo ano

em que Billie, sentada, deixava

que filmassem a sua morte.

Ainda assim, Billie gostou de Moody,

percebeu a diferença entre um eco

e uma cópia, a força insuportável do acaso.
}

Não há imitação em arte, não há caminhos.

Só por milagre, e muito raramente, 
duas vozes se encontram tão perto do silêncio. (Freitas 2011: 11)

O poema fala do encontro casual entre dois destinos de mulheres e de artistas. Tratase de duas figuras com nomes e dados biográficos reais que, no texto poético, misturam-se a detalhes criados pela imaginação do poeta para dar ainda mais profundidade ao lastro existencial das personagens. Todavia, se pensarmos em termos de alegoria, podemos ver aí ainda um outro encontro, aquele que o acaso promove entre a poesia e a música, essas "duas vozes" que também "se encontram tão perto do silêncio". Nesse sentido, pode-se, inclusive, explorar a concepção do poema enquanto eco da canção musical, algo que, como sugerem os próprios versos de Freitas, é diferente da mera cópia.

O eco é, em primeiro lugar, a repetição de algo. Entretanto, em arte, a repetição sempre implica diferença. Em "Uma didática da invenção", poema de O livro das ignorãças, o poeta brasileiro Manoel de Barros (2010: 300) registra os seguintes versos: "Repetir repetir - até ficar diferente. / Repetir é um dom do estilo". É nesse sentido de invenção e de recriação que procuro compreender o diálogo com a música que Freitas empreende em seu livro, todo ele concebido como uma resposta ou ressonância ao disco Moody, o único gravado por Marilyn Moore em sua breve carreira musical.

No primeiro poema do livro, Freitas dispõe os seguintes versos:

Moody, porém, faz-nos repensar a história,

obriga-nos a escutar o vento. (Freitas 2011: 7)

A meu ver, o poeta busca no álbum de Moore não apenas o clima melancólico que o próprio adjetivo em inglês sugere ("moody"), como também a perspectiva de um ato que transcenda à circunstancialidade dos fatos biográficos, na medida em que o trecho acima constitui os versos finais de um poema em que são mencionados, com extrema concisão poética, o nascimento e a morte da artista estadunidense: “Oklahoma, 1931". Refiro-me, precisamente, ao ato de audição musical por parte do poeta, que aqui ganha caráter inventivo, tanto no que se refere a certa licença poética de recriação da biografia de Marilyn Moore, de Billie Holiday e demais personagens reais em torno de ambas, quanto (e, para isso, é necessário considerar o aspecto alegórico dos versos) no tocante a alguns impasses 
da escritura poética em nossos dias, cuja história é aqui repensada em termos de aproximação com o universo musical.

Pode-se, aliás, verificar o modo como esse processo inventivo é articulado observando-se a retomada dessa menção ao "vento" dois poemas adiante, em um texto no qual, sob outro título homônimo a uma canção de Moore - "Ill wind" - uma voz em primeira pessoa, como se fosse a do próprio poeta, acentua, a meu ver, o viés alegórico e autorreferencial que venho sublinhando:

\footnotetext{
Se eu fosse Deus - a mais indigna

das profissões - , convidava

Tom Waits para completar este dueto.
}

Pois o vento, já se sabe, empurra-nos

sempre para a morte. (Freitas 2011: 12)

Ora, essa via alegórica permite compreender "este dueto" não mais como o encontro entre as duas cantoras, mencionado em "I'm just a lucky so and so", e também não somente como a parceria entre Moore e Al Cohn, ao executarem as canções de Moody. Trata-se, em última instância, de uma interação entre o poeta e o músico, sendo este último simbolizado, agora, por Tom Waits, artista da música experimental norte-americana com trânsito por vários estilos, como rock, blues, jazz etc. Nesse processo, o gesto de escuta - a escuta poética da canção -, que tem como ponto de partida o recurso à biografia, como artifício de máscara poética, conforme foi dito na seção anterior, acaba por apontar para certa crise que não diz respeito somente ao destino trágico de Marilyn e Billie, essas mulheres que cantam e cujo canto é calibrado por suas dores e paixões.

"Pois o vento, já se sabe, empurra-nos / sempre para a morte", diz Freitas, em um tom melancólico que ecoa a música de Moore. Ecoar, fazer eco à canção é, certamente, o gesto mais relevante do poema nessa escritura em dueto, em que a poesia, mais do que mera repetição ou "cópia", é concebida em um fluxo interdiscursivo com a música, da qual se distingue ao mesmo tempo em que se aproxima. Aliás, no próprio gesto reflexivo de distinção ou diferenciação realizado pelo poeta em relação à arte do músico reside, a meu ver, a porção de inventividade do poema, a partir de um gesto intersubjetivo. 
Por fim, cabe observar que, além de repetição, o eco define-se como vocalidade vestigial. Eco, na mitologia grega, é a ninfa que, por sua tagarelice, foi castigada pela deusa Hera a só repetir o que os outros diziam e que, por desilusão amorosa provocada pelo desprezo de Narciso, por quem em vão se apaixonara, definhou, reduzindo-se à própria voz. No livro de Manuel de Freitas, a poesia, cuja condição é alegorizada pela trajetória artística e pessoal de Marilyn Moore, assemelha-se a esta ninfa. Como se diz no poema "Trav'lin' all alone", a poesia é essa "voz que / vai ficando sozinha, / cada vez mais sozinha. // Até por fim se confundir / com a noite" (Freitas 2011: 22). Em outro poema do mesmo livro, "You're driving me crazy", título também homônimo a uma canção do disco de Moore, a voz pode ser, mais uma vez, compreendida como elemento comum entre a biografia poética da cantora e a condição da poesia na contemporaneidade: "A sua voz pedia um quase murmúrio, / era incompatível com o estrépito em voga / e demasiado frágil para atrair os boppers" (idem: 21).

Desta feita, a poesia, ao reescrever a música, escreve-se, faz a própria autobiografia. E o faz, vale dizer, de modo metonímico, sombrio, precário. 


\section{NOTAS}

${ }^{1}$ Eis a letra da canção: "They're writing songs of love, but not for me / A lucky star's above, but not for me / With love to lead the way / I've found more clouds of grey / Than any russain play could guarantee / I was a fool to fall and get that way / Heigh-ho! alas! and also, lack-a-day! / Although I can't dismiss the mem'ry of his kiss / I guess he's not for me // He's knocking on a door, but not for me / He'll plan a two by four, but not for me / I know that love's a game / I'm puzzled, just the same / Was I the moth or flame? / I'm all at sea / It all began so well, but what an end! / This is the time a feller needs a friend / When ev'ry happy plot ends with the marriage knot / And there's no knot for me". (Gershwin / Gershwin 1930)

2 Tais como: Büchlein für Johann Sebastian Bach (2003), Blues for Mary Jane (\& etc.) (2004), Aria Variata (2005), Jukebox (2005), com continuações em 2008, 2009 e 2012, e Intermezzi, Op. 25 (2009), além de Walkmen (\& etc.), em parceria com José Miguel Silva, e Canções Usadas (2009), em parceria com Rui Pires Cabral, entre outros.

${ }^{3}$ Esta é a letra da canção, também conhecida pelas interpretações de Billie Holiday, em dueto com Ella Fitzgerald (1958), e Barbra Streisand (1962): "You went away / I let you / We broke the ties that bind / I wanted to forget you / And leave the past behind / Still, the magic if the night I met you / Seems to stay forever in my mind // The sky was blue / And high above / The moon was new / And so was love / This eager heart of mine was singing / Lover where can you be / You came at last / Love had its day / That day is past / You've gone away / This aching heart of mine is singing // Lover come back to me / When I remember every little thing / You used to do / I'm so lonely / Every road I walk along / I walk along with you / No wonder I am lonely / The sky is blue / The night is cold / The moon is new / But love is old / And while I'm waiting here / This heart of mine is singing / Lover come back to me // When I remember every little thing / You used to do / I grow lonely / Every road I walk along / I walk along with you / No wonder I am lonely / The sky is blue / The night is cold / The moon is new / But love is old / And while I'm waiting here / This heart of mine is singing / Lover come back to me". (Romberg / Hammerstein 1928)

4 “I'm so weary and all alone / Feel tired like heavy stone / Trav'lin', trav'lin' all alone / Who will see and who will care / Bout this load that I must bear / Trav'lin', trav'lin' all alone / Prayers are said to heaven above / 'bout my burdens, woes and love // Head bowed down with misery / Nothing now appeals to me / Trav'lin', trav'lin' all alone // Give me just another day / There's one thing I want to say / Friends are well when all is gold / Leave you always when you're old / Trav'lin', trav'lin' all alone". (Johnson 1929) 


\section{Bibliografia}

Barros, Manoel de (2010), Poesia Completa, São Paulo, Leya.

Freitas, Manuel de (2007), Poemas, Coleção Portugal 0, Rio de Janeiro, Oficina Raquel.

-- (2010), A Última Porta, antologia, Lisboa, Assírio \& Alvim.

-- (2011), Marilyn Moore, desenhos de Adriana Molder, Lisboa, Assírio \& Alvim.

Gershwin, George / Gershwin, Ira (1930), "But Not For Me", <https://www.azlyrics.com/ lyrics/billieholiday/butnotforme.html> (último acesso em 30/04/2019).

Johnson, J. C. (1929), “Trav'lin' All Alone”, <https://lyricsplayground.com/alpha/songs/t/ travlinallalone.html> (último acesso em 30/04/2019).

Man, Paul de (1999), O Ponto de Vista da Cegueira. Ensaios Sobre a Retórica da Crítica Contemporânea, tradução de Miguel Tamem, Braga, Coimbra, Lisboa, Angelus Novus \& Cotovia.

-- (2012). "Autobiografia como des-figuração", Sopro, panfleto político-cultural, no 71 <http://www.culturaebarbarie.org/sopro/outros/autobiografia.html\#.XMit5-hKjlV> (último acesso em 30/04/2019).

Martelo, Rosa Maria (2004), Em Parte Incerta. Estudos de poesia portuguesa moderna e contemporânea, Porto, Campo das Letras.

Meschonnic, Henri (2009), Critique Du Rythme. Antropologie historique du language, Paris, Verdier.

Romberg, Sigmund / Hammerstein, Oscar (1928), "Lover, Come Back To Me", <https://songmeanings.com/songs/view/3530822107858929198/> (último acesso em 30/04/2019).

Silveira, Jorge Fernandes / Luis Maffei (2011), Poesia 61 Hoje, Rio de Janeiro, Oficina Raquel. Vasconcelos, Vasco André Ribeiro de (2010), Música, Fatalmente. Referências musicais na poesia de Manuel de Freitas, dissertação de mestrado da Universidade do Porto. 
Patrícia Chanely Silva Ricarte é pesquisadora em estágio pós-doutoral na Universidade Federal de Minas Gerais, com financiamento do Programa Nacional de Pós-Doutorado da Coordenação de Aperfeiçoamento de Pessoal de Nível Superior (PNPD/CAPES), do Ministério da Educação brasileiro. É doutora em Literatura pela Universidade Federal de Santa Catarina (UFSC) e mestre em Letras e Linguística (Estudos Literários) pela Universidade Federal de Goiás (UFG). Está vinculada ao Pólo de Pesquisa em Poesia Portuguesa Moderna e Contemporânea, sediado na UFMG, em Belo Horizonte, Minas Gerais, Brasil. 